\title{
The prevalence of caries, def-t, and DMF-T index of children with Down Syndrome aged 6-14 years old
}

\author{
Nor Fatihah Azhar*, Eriska Riyanti*, Iwan Ahmad M* \\ *Department of Pedodontics Faculty of Dentistry Universitas Padjadjaran, Indonesia
}

\begin{abstract}
Down syndrome is a common genetic disorder also known as Trisomy 21. There are special orofacial features of children with Down syndrome in contrast to normal children. The increasing occurrence of dental caries in Down syndrome children may be caused by the exposure towards cariogenic foods nowadays. This research was aimed to determine the prevalence of caries, def-t, and DMF-T index of 6-14 years old children with Down syndrome at Bandung in 2011. This study was a descriptive study with the surveying technique. The population of this research was the Down syndrome students of Special School (SLB) in Bandung City region with the age range of 6-14 years old. The Special Schools participated in this study were Muhammadiyah Special School; YPLB C-Special School; Asih Manunggal C- Special School; Terate S-Special School; Aditya Grahita BC-Special School; and YPLB Cipaganti BC-Special School. The sample of this research was 30 students. The caries prevalence, def-t, and DMF-T index of the students was measured by the examination of decayed, extracted or missing, and filled teeth. The research results showed that the prevalence of caries was 93\%, while the def-t index was 3.03 and DMF-T index was 6.1. The conclusion of this research was the caries prevalence of children with Down syndrome was very high, whereas the def-t index was categorized in the moderate level, and the DMF-T index was categorized in the high level.
\end{abstract}

Keywords: Down syndrome, caries prevalence, def-t index, DMF-T index

\section{INTRODUCTION}

Dental caries is a chronic endogenous infection caused by the normal oral commensal flora. The carious lesion is the result of demineralization of the tooth enamel and dentine by acids produced by the plaque microorganisms as they metabolize dietary carbohydrates. However, the initial process of enamel demineralization is usually followed by remineralization and cavitations occurred after. Once the surface layer of the enamel has lost, the infection invariably progresses to the dentine, with the pulp become the first to inflamed then necrotic. Caries defined as localized destruction of the dental tissues by bacterial fermentation of dietary carbohydrates. ${ }^{1}$

From other definition, caries is a destructive process causing decalcification of the tooth enamel and leading to the advanced destruction of enamel and dentine, and cavitations of the tooth. ${ }^{2}$ Caries is a fermentation of dietary sugars become organic acids by microorganisms in plaque on the tooth surface. The major factors involved in the etiology of caries are host factors (tooth, saliva), 
dietary habit (mainly the intake of fermentable carbohydrates), and plaque microorganisms such as supra-gingival plaque.

According to Al-Khadra in 2000, the prevalence of caries in individuals with Down syndrome was very high. The prevalence of caries among the study sample was $89 \%$. In the 3-6 years old age group, the average value of def- $t$ (decayed, missing, filled primary teeth) score was $4.71 \pm 1.27$. In the $7-14$ years old age group, the average value of def-t and DMF-T scores were $6.09 \pm 2.34$ and $3.93 \pm 1.64$, respectively. ${ }^{3}$ From other research conducted by Casthilo et al. in 2007 discovered that the caries prevalence was increased along with age in individuals with Down syndrome. ${ }^{4}$ According to the results of caries indexes, the study samples had average values of 4.53 and 6.85 for DMF-T and DMF-S index, respectively, whereas the dmf-t and dmf-s index were 1.55 and 2.55 , respectively. As much as twenty-one $(36 \%)$ individuals were caries-free; seventeen (29\%) of them were children (from 1-12 years old), and four (7\%) of them were adults. ${ }^{3}$

From the previous research can be concluded that children with Down syndrome had a high caries experience, with only a few of them had a good oral hygiene. The increasing occurrence of dental caries in Down syndrome children may be caused by the exposure towards cariogenic foods nowadays. There are only a few institutionalized populations of Down syndrome nowadays with controlled dietary habit. The caries incidence in the children may be affected by a delayed tooth eruption, increased interdental space, or possible differences in the chemical contents of the saliva. ${ }^{5}$ Oral health of disabled children may be neglected too due to their disability condition. Moreover, because of their limited ability and willingness to undergo an oral examination leads to a bad oral health condition. Gross motor developments of Down syndrome children are slower compared to normal children. The lack of motoric skills causes the children had poor oral health because they cannot perform the proper oral health care, and eventually will cause the high caries prevalence.

Down syndrome children also have a thicker tongue, and the muscle tone often looser than the normal children causes difficulty in masticating. Anatomically, however, the shape and condition of their oral cavity make them less exposed towards caries development because of the microdontia that makes foods did not tend to trapped and initiated caries. ${ }^{6}$

In the past few years, concern towards disabled group was rising, and several studies had performed in measuring the oral health status of disabled children. In Indonesia, the prevalence of Down syndrome was more than 300,000 cases annually, and relatively high compared to the prevalence of Down syndrome in the United States which only range from 3000 to 5000 cases annually. Down syndrome is the most prevalent chromosomal abnormality found in humans. ${ }^{7}$ It is a genetical disorder disease, which Trisomy 21 as the most common genotype. Down syndrome children nowadays are more advanced developmentally, and showed better social skills. Even though mental retardation was the main feature of Down syndrome and covered $17 \%$ of mental retardation cases in the United States, ${ }^{8}$ it is important to realize that the progress in learning and developing in Down syndrome children is still possible. They are more directable and have more manageable behavioral problems than individuals with other mental retardation cause. If they are taught to take care of themselves, these children will be able to be independent and taking care of themselves well enough.

The precise prevalence of dental caries in Down syndrome individuals was still unclear. According to Latner in 1983, the studies regarding caries prevalence in Down syndrome individuals were unclear. ${ }^{9}$ Some studies revealed a significant low caries prevalence in Down syndrome individuals compared to non-Down syndrome individuals, while other studies showed higher caries prevalence in this group.

From the early observation, Down syndrome children in Bandung, Indonesia, were given special care and attention at schools and from their parents. Their parents apparently understand the condition of their children and very responsible for helping the growth and development of their children. There are lots of special schools in Bandung which welcomed and served the needs of these children regarding their academic knowledge, and also their motoric and social skills. This research was aimed to determine the prevalence of caries, def-t, and DMF-T index of 6-14 years old children with Down syndrome at Bandung in 2011. 


\section{METHODS}

The type of this research was descriptive with surveying technique. The population of this research was the Down syndrome students of Special School (SLB) in Bandung City region with the age range of 6-14 years old with a total sample of 30 Down syndrome children.

The samples criteria were as follows: Suffering Down syndrome (including all three types of Down syndrome, Type 1, non-disjunction; Type 2, translocation; and Type 3, mosaicism); aged from 6-14 years old; having an average oral health condition; the IQ level was from 30-70 (mild to moderate mental retardation); able to provide the basic self-needs; have varying degrees of educational achievement and also social and occupational skills; and willing (or represented by their parents) to participate in this study and filled in the informed consent. A multi-stage cluster random sampling was used to choose the samples. Bandung was divided into five regions which were North Bandung, South Bandung, Central Bandung, West Bandung, and East Bandung. The sample selections were performed with consideration of this regional division.

A population sample was then selected from the non-stratified random sampling of special schools in Bandung, and six special schools met the criteria required for the sample were selected. They were Muhammadiyah Special
School; YPLB C-Special School; Asih Manunggal C- Special School; Terate S-Special School; Aditya Grahita BC-Special School; and YPLB Cipaganti BCSpecial School.

\section{RESULTS}

Examination results from as much as 30 samples of Down syndrome children from 6 special schools in Bandung were collected, analyzed and calculated to determine the caries prevalence, def-t, and DMF-T index.

Table 1 showed gender distribution and total sample amount that studied at C-Special School participated in this study and picked randomly by the non-stratified random sampling method. In this study, the total sample amount was 30 individuals. These samples consisted of those who met the selection criteria with 14 (47\%) male and $16(53 \%)$ female special school students. From the clinical observation results were obtained the caries prevalence, def-t, and DMF-T index as shown in Table 2 below.

Table 2 showed the caries prevalence of Down syndrome special school students at Bandung in 2011. The results showed that the total caries prevalence for all 6 schools selected was $93 \%$ with a total of 28 students having caries.

Table 3 showed the total def value and def-t index of Down syndrome children. The total def value of the Down syndrome special school

Provinces $\longrightarrow$ Cities/Regencies $\longrightarrow$ Regions $\longrightarrow$ Schools $\longrightarrow$ Special Schools

Figure 1. Multi-Stage sampling method

Table 1. Distribution of gender and sample amount at C-Special Schools participated

\begin{tabular}{cccc}
\hline School & Male & Female & Sample amount \\
\hline Yayasan Terate C-Special School & 2 & 3 & 5 \\
Asih Manunggal C-Special School & 3 & 4 & 7 \\
YPLB Cipaganti C-Special School & 2 & 4 & 6 \\
Muhammadiyah C-Special School & 1 & 4 & 5 \\
Aditya Grahita C-Special School & 3 & 0 & 3 \\
YPLAB C-Special School & 3 & 1 & 4 \\
\hline Total & 14 & 16 & 30 \\
\hline
\end{tabular}

Table 2. Prevalence of caries in Down syndrome special school students in Bandung

\begin{tabular}{cccc}
\hline School & Total Student & Student infected with caries & Prevalence \\
\hline 6 special schools represented all Bandung regions & 30 & 28 & $93 \%$ \\
\hline
\end{tabular}


Table 3. Def-t index of Down syndrome special school students in Bandung

\begin{tabular}{|c|c|c|c|c|c|c|}
\hline \multirow{2}{*}{ Value } & \multicolumn{4}{|c|}{ Total } & \multirow{2}{*}{$\begin{array}{c}\text { Total } \\
\text { student }\end{array}$} & \multirow{2}{*}{ Index } \\
\hline & d & e & $f$ & def & & \\
\hline Tooth amount & 81 & 10 & 0 & 91 & 30 & 3.03 \\
\hline
\end{tabular}

Table 4. DMF-T index in Down syndrome special school students in Bandung

\begin{tabular}{ccccccc}
\hline \multirow{2}{*}{ Value } & \multicolumn{4}{c}{ Total } & \multicolumn{2}{c}{ Total } \\
student & Index \\
\cline { 2 - 5 } & D & M & F & DMF & & \\
\hline Tooth amount & 166 & 13 & 4 & 183 & 30 & 6.1 \\
\hline
\end{tabular}

students was 91, and the def-t index was 3.03. From the latest index criteria of WHO, the def-t index of Down syndrome special school students at Bandung was included in the moderate criteria. ${ }^{10}$

Table 4 contained the total DMF value and DMF-T index of the Down syndrome special school students at Bandung. The total DMF value was 183 , and the DMF-T index was 6.1 , which classified in the high criteria. 10

\section{DISCUSSION}

The results from this study showed that the caries prevalence in Down syndrome special school students at Bandung in 2011 was $93 \%$, the def-t index was 3.03, and the DMF-T index was 6.1. According to the World Health Organization, the def-t index result was classified as moderate, while the DMF-T index was classified as high.

Based on the age aspect, the period of age selected in this study was the mixed dentition periods. During this period, most of the primary teeth were at the exfoliation time, and some of them have begun to decay. Kennedy had stated in 1992 that the caries experience would increase during the mixed dentition periods. The primary teeth tended to decay during this period compared to the permanent teeth. This condition was because of the less solid and thinner structure of the primary teeth enamel compared to the permanent teeth. The primary teeth morphology also enabled the food retention accumulation. ${ }^{11}$

The DMF-T index of Down syndrome children in Bandung was 6.1, which classified as high. It was higher compared to the def-t index, which was only 3.03 , and classified as moderate. ${ }^{10}$ This condition might be caused by the longer duration of the permanent teeth in the oral cavity. Time is one of the contributing factors of the caries occurrence. During the early stage of mixed dentition period, many children will have their all four first permanent molars erupting, and also the exfoliation of primary central and lateral incisors that soon will be replaced by permanent teeth. By the end of the twelfth year, all the permanent molars teeth usually have erupted. ${ }^{12}$

Based on the results of the questionnaire can be concluded that most of Down syndrome children were having a fair to poor oral hygiene. Oral hygiene plays an important role in the initiation and progression of dental caries and periodontal disease. ${ }^{13}$ From the questionnaire results, as much as $53.3 \%$ of them only brush their teeth once a day, while $43.3 \%$ of them brush their teeth twice a day, and only $3.33 \%$ of them brush their teeth three times a day. The teeth should be cleaned thoroughly at least twice a day using fluoride toothpaste. Toothbrushing helps to remove the plaque and food particles that are retentive to the tooth surface. Regular toothbrushing will also keep the gums healthy. ${ }^{14}$ According to Manson in 1993, the best time to brush the teeth were after breakfast and before bedtime. ${ }^{15}$

Only $16.7 \%$ of Down syndrome children followed the rules of brushing teeth after breakfast and before bedtime, while most of the children (80\%) choose to brush their teeth only when they take a bath. As stated in many previous research, a delayed eruption will decrease the caries prevalence index. However, in this research, this theory cannot be proven because most of Down syndrome children had a quite normal tooth eruption, means fully erupted at the age of 12 years old, most of them have complete permanent teeth, ignoring the fact that there was few tooth persistency found in few subjects. Over-retained primary teeth may give the patient a double row of teeth, especially in the condition due to the lack of permanent teeth presence or delayed permanent teeth eruption. ${ }^{16}$

There's only few institution provides a full care for Down syndrome individuals nowadays. Such institution will strictly control the dietary habits of Down syndrome individuals, ${ }^{5}$ thus will decrease the caries prevalence. ${ }^{5}$ Dietary habits 
control would help to prevent Down syndrome children from caries. Exposure towards cariogenic foods was unhealthy for them because compared to normal children, their ability to take care of themselves were quite limited. ${ }^{17}$ From the questionnaire results, as much as $80 \%$ of the children said that they like sweets, candies, and chocolates. However, only $20 \%$ of them rinse and gargle their mouth after eating sweet foods. This condition was one of the contributing factors of the high caries prevalence, def-t, and DMF-T index. After eating sweets or snacks, it is very advisable for the children to rinse their mouth or brush their teeth to remove all the retentive plaque that will initiate caries. An increase in dietary carbohydrates, particularly sucrose, resulted in an additional acid production that may exceed both the capacity of the saliva to remove acid products and the neutralizing power of the salivary/plaque buffer system which resulted in more frequent acidification of the plaque. ${ }^{18}$ Diet containing sucrose was one of the main cause for the high prevalence of dental caries rate in developed countries. ${ }^{19}$

The results of this study also showed that 63.3\% of Down syndrome children had experience toothache. As much as $53.3 \%$ of them said that cavities caused the toothache, while $20 \%$ of them said that gum bleeding caused their toothache. As much as $26.7 \%$ of the children had experience painful and uncomfortable swollen gum. To relieve the pain, $13.3 \%$ of them chose to take medicine, $10 \%$ of them preferred to go to the dentist to treat the toothache, while $76.7 \%$ of them choose to leave it to healed by time. Dental caries is an infectious microbiological disease of the teeth resulted in localized dissolution and destruction of the calcified dental tissues. When the process of destruction reaches the second layer of the tooth (dentine) will cause the patients to feel the soreness when drinking a cold or hot drinks. In the later stages, dental caries will cause severe pain, was expensive to treat and lead to the loss of precious time. ${ }^{20}$

As much as $96.7 \%$ of the students were doing the last visit to the dentist more than one year ago. As much as $20 \%$ of them only visit the dentist when they were experiencing toothache, while the majority of them $(76.7 \%)$ never go to the dentist. Most of them (70\%) were apparently afraid to go to the dentist (dental fear), so we can concluded that there was still lack of dental health education for Down syndrome children in Bandung. Nowadays, Down syndrome children should be educated with the proper oral health care method and received the benefits of both systemic and topical fluoride treatment. Occlusal sealants are also recommended, and the primary tooth decay should get immediate treatment. Obviously, a good home care is essential in the management of dental disease. However, this condition may be difficult to achieve with the intellectual impairment and a manual dexterity decrease seen in Down syndrome. It is important for a Down syndrome children parents, family, or caregiver to be educated of the proper home care as well. ${ }^{21}$

\section{REFERENCES}

1. Samaranayake L. Essential Microbiology for Dentistry. $3^{\text {rd }}$ ed. London: Churchill Livingstone; 2006.

2. Dorland. Dorland's Pocket Medical Dictionary (Dorland's Medical Dictionary). $26^{\text {th }}$ ed. Philadelphia: Saunders-Elsevier; 2001.

3. Al-Khadra TA. Prevalence of dental caries and oral hygiene status among down's syndrome patients in Riyadh - Saudi Arabia. Pakistan Oral Dent J. 2011;31(1):115-7.

4. de Castilho ARF, Pardi V, Pereira CV. Caries prevalence, level of mutans streptococci, salivary flow rate and buffering capacity in subjects with Down syndrome. Braz J Oral Sci. 2007;6(21):1331-6.

5. Morinushi T, Lopatin DE, Tanaka H. The relationship between dental caries in the primary dentition and anti S. mutans serum antibodies in children with Down's syndrome. J Clin Ped Dent. 1995;19(4):279-84.

6. Pilcher ES. Dental care for the patient with Down syndrome. J Down Syndrome Res Prac. 1998;5(3):111-6.

7. Darby ML, Walsh M. Dental Hygiene Theory and Practice Textbook. 1st ed. Philadelphia: Saunders-Elsevier; 1995.

8. Spencer WD, Raz N. Selective neuroanatornic abnormalities in Down's syndrome and their cognitive correlates Evidence from MRI morphometry. Neurol. 1995;45:356-66. 
9. Latner LE. The caries experience in three genotypes of Down's syndrome. J Pedod. 1983 Winter;7(2):83-90.

10. WHO. Oral Health Surveys: Basic Methods 4th edition. Geneva: WHO Library; 1997.

11. Suwelo IS. Karies Gigi Pada Anak Dengan Pelbagai Faktor Etiologi : Kajian Pada Anak Sekolah. Jakarta: EGC; 1997.

12. Pinkham JR. Pediatric Dentistry: Infancy Through Adolescence. $4^{\text {th }}$ ed. Philadelphia: Saunders-Elsevier; 2005.

13. Sheiham A, Watt RG. The common risk factor approach: a rational basis for promoting oral health. Community Dent Oral Epidemiol. 2000 Dec;28(6):399-406.

14. MCNeil PL, Miyake K. Damage caused by brushing may help keep gums healthy says new research. Brit Dent J. 2007;203(4):179.

15. Fitzsimons D, Dwyer JT, Palmer C, Boyd LD.
Nutrition and Oral Health Guidelines for Pregnant Women, Infants, and Children. J Amer Diet Assoc. 1998;98(2):182-9.

16. Muller HP, Schaller N, Eger T, Heinecke A. Thickness of masticatory mucosa. J Clin Periodontol. 2000;27(6):431-6.

17. Tarek M. The baby with Down syndrome. ASJOG. 2005;2:362-5.

18. Trahan L, Bareil M, Gauthier L, Vadeboncoeur C. Transport and Phosphorylation of Xylitol by a Fructose Phosphotransferase System in Streptococcus mutans. Caries Res 1985;19:5363.

19. Shah N. Geriatric dentistry: the need for a new specialty in India. Nat Med J India. 2005 Jan-Feb;18(1):37-8.

20. Boyd D, QuickA, Murray C. The Down syndrome patient in dental practice, Part II: clinical considerations. NZDent J. 2004Mar;100(1):4-9. 